Only $12 \%$ had moderate and $6 \%$ had severe arthritis. Similarly, only $10 \%$ had moderate and $7 \%$ had severe psoriasis. During and following pregnancy, about half of all patients reported no change in either joint or skin activity during and follow pregnancy, with fairly equal numbers reporting improved and worsened arthritis. On the other hand, $42 \%$ had improved psoriasis during pregnancy compared to $6 \%$ with worsened. There did not appear to be a significant postpartum flare.

Conclusions: Our analysis found that among women with PsA who have tried to become pregnant, $36 \%$ experienced infertility, primarily due to PCOS. Compared to pregnancies occurring before the diagnosis of PsA, pregnancies after PsA diagnosis had a lower frequency of live births and a higher frequency of preterm births. Overall, in this cohort of women with mostly mild disease during pregnancy, arthritis pain and psoriasis activity did not appear to substantially worsen during pregnancy. Acknowledgements: This study was funded by Janssen.

Disclosure of Interest: None declared

DOI: 10.1136/annrheumdis-2017-eular.6392

\section{SAT0467 ALL 10-YEAR CARDIOVASCULAR RISK SCORES ARE SIMILAR IN PATIENTS WITH PSORIATIC ARTHRITIS AND PSORIASIS}

N. Ikumi ${ }^{1}$, F. Farkas ${ }^{1}$, A. Szentpetery ${ }^{1}$, B. Kirby ${ }^{2}$, O. FitzGerald ${ }^{1}$

${ }^{1}$ Rheumatology; ${ }^{2}$ Dermatology, St. Vincent's University Hospital, Dublin, Ireland

Background: Psoriatic arthritis ( $\mathrm{PsA}$ ) and Psoriasis (PsO) are associated with higher cardiovascular (CV) risk with higher risk in patients with a severe disease phenotype ${ }^{1,2}$. Long-term CV risk is evaluated using several methods for the general population.

Objectives: The aim of the study was to compare CV risk factors and 10-year $\mathrm{CV}$ risk scores between patients with PsA and those with $\mathrm{PsO}$ only.

Methods: PsA patients fulfilling the CASPAR criteria and PsO with disease duration $<10$ years were enrolled consecutively from Rheumatology and Dermatology clinics. Fasting bloods were obtained for glucose, insulin and lipids. Patients underwent thorough physical examination, joint and skin assessments and completed questionnaires on health and quality of life. Four different CV risk scores were calculated: (1) Framingham Coronary risk score (FCS); (2) American College of Cardiology and American Heart Association (ACC/AHA) 10year atherosclerotic cardiovascular disease (ASCVD) algorithm; (3) Systematic Coronary Risk Evaluation (SCORE) algorithm; and (4) QRISK2 (2016).

Results: 232 patients (100 PsA and $132 \mathrm{PsO}$ ) were recruited with mean age $52.4( \pm 10.5)$ for PsA and $39.7( \pm 14.4)$ for PsO. Mean disease duration for PsA was $17.9( \pm 10)$ years. There were significantly more patients with hypertension (HTN) and metabolic syndrome in PsA group, and the patients taking DMARDs and/or biologics treatment were also higher compared to PsO. Fasting glucose, insulin, lipids, BMI and waist/hip ratio did not show significant differences. The mean FCS, ASCVD, SCORE and QRISK2 were significantly higher in $\mathrm{PsA}$ as compared to $\mathrm{PsO}(7.6 \pm 7.0 \%$ vs. $4.7 \pm 6.1 \%, \mathrm{P}=0.0002 ; 8.4 \pm 8.2 \%$ vs. $4.5 \pm 5.8 \%, P<0.0001 ; 2.1 \pm 2.6 \%$ vs. $1.1 \pm 1.8 \%, P=0.0002 ; 11.2 \pm 9.9 \%$ vs. $5.2 \pm 6.4 \%, P<0.0001$, respectively). However, after adjusting for age and sex, all $\mathrm{CV}$ risk scores were similar $(\mathrm{P}=0.21)$. Multiple regression analysis revealed that waist/hip ratio significantly correlated with all CV risk scores in both PsA and PsO. Conclusions: We found similar 10-year risk of CVD in PsA and PsO patients using FCS, ASCVD, SCORE and QRISK2. Waist/hip ratio had significant effect on all CV risk scores suggesting that central obesity should be managed appropriately to reduce long-term CVD in psoriatic disease.

References:

[1] Eder L. Ther Adv Musculoskel Dis 2015.

[2] Ogdie A. ARD 2015.

Disclosure of Interest: N. Ikumi: None declared, F. Farkas: None declared, A. Szentpetery: None declared, B. Kirby Grant/research support from: abbie, O. FitzGerald Grant/research support from: abbie, Pfizer, BMS, Consultant for: abbie, Pfizer, BMS, Celgene, Janssen, Novartis, UCB, Eli Lilly DOI: 10.1136/annrheumdis-2017-eular.4404

\section{SAT0468 PRESENCE OF POOR PROGNOSTIC FACTORS MAY PREDICT RESPONSE TO ABATACEPT IN PATIENTS WITH ACTIVE PSORIATIC ARTHRITIS: RESULTS FROM A POST HOC ANALYSIS FROM A PHASE III STUDY}

P. Mease ${ }^{1}$, I. Mclnnes ${ }^{2}$, V. Strand ${ }^{3}$, O. FitzGerald ${ }^{4}$, H. Ahmad ${ }^{5}$, A. Johnsen ${ }^{5}$, J. Ye ${ }^{5}, \mathrm{~S}$. Banerjee ${ }^{5}$. ${ }^{1}$ Swedish Medical Center and University of Washington, Seattle, United States; ${ }^{2}$ University of Glasgow, Glasgow, United Kingdom; ${ }^{3}$ Stanford University, Palo Alto, United States; ${ }^{4}$ St Vincent's University Hospital and University College Dublin, Dublin, Ireland; ${ }^{5}$ Bristol-Myers Squibb, Princeton, United States

Background: Abatacept, a selective T-cell co-stimulation modulator, significantly increased ACR20 response and had an overall beneficial effect on musculoskeletal symptoms in patients (pts) with active psoriatic arthritis (PsA) in the Phase III Active pSoriaTic athritis RAndomizEd triAI (ASTRAEA, NCT01860976). ${ }^{1}$ Factors that may predict responses to abatacept were explored in this post hoc analysis. Objectives: To evaluate the relationship between baseline characteristics and abatacept response in a post hoc analysis of ASTRAEA.
Methods: Pts were randomized (1:1) to SC abatacept $125 \mathrm{mg}$ weekly or placebo for 24 weeks in this trial. Pts without $>20 \%$ improvement in joint counts at Week 16 were switched to open-label abatacept (early escape). ACR20 response rate in pts stratified by baseline variables was investigated in a multivariate analysis and odds ratios (ORs) generated to identify differences in response. Using a cut-off of OR 1.2, indicating pt subgroups in whom abatacept appeared to have a meaningful treatment benefit, baseline variables were further investigated in a univariate analysis and estimated differences calculated.

Results: Of 424 pts enrolled, 213 received abatacept and 211 placebo. In abatacept-treated pts, the multivariate model showed a difference in ACR20 response (OR $>1.2$ ) for baseline CRP (>upper limit of normal [ULN] vs $\leq$ ULN; OR $1.346[95 \% \mathrm{Cl} 0.668,2.712])$, DAS28 (CRP) (>5.1 vs $\leq 5.1 ; 1.489[0.782$, $2.836]$ ), dactylitis ( $>0$ vs $0 ; 1.372[0.708,2.659]$ ), and median baseline erosions ( $\geq 3$ vs $<3 ; 1.924[1.032,3.587]$ ). In placebo-treated pts, the OR was $>1.2$ for dactylitis only $(1.406[0.619,3.193])$. These factors, which have been identified previously as indicating poor prognosis in PsA, were balanced between treatment arms at baseline. In the univariate model by poor prognostic factors, the differences in ACR20 response rates with abatacept treatment vs placebo in distinct subgroups were numerically greater in pts who were positive for these prognostic factors at baseline than in those who were not (Figure).

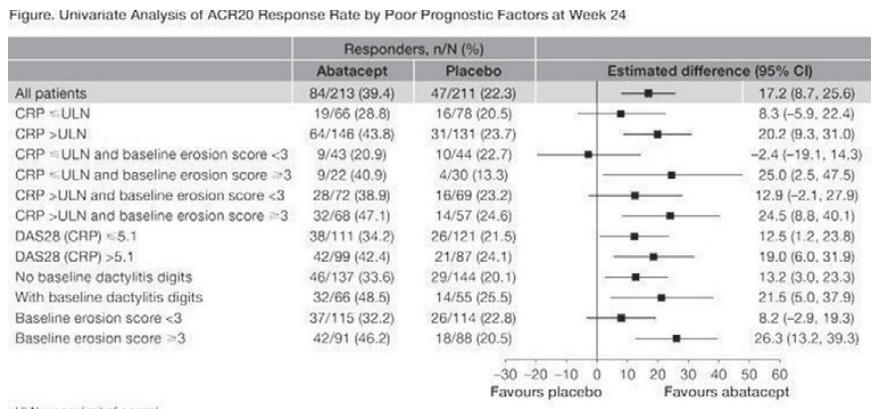

Conclusions: These findings identified subgroups of pts with PsA with certain baseline characteristics in whom abatacept is most likely to be effective. The predictive factors identified are aligned with poor prognostic factors in the EULAR and Group for Research and Assessment of Psoriasis and Psoriatic Arthritis (GRAPPA) guidelines, ${ }^{2,3}$ and may indicate pts with the highest unmet medical need.

\section{References:}

[1] Mease P, et al. Arthritis Rheumatol 2016;68(Suppl 10):[Abstract 1041].

[2] Gossec L, et al. Ann Rheum Dis 2016;75:499-510.

[3] Coates L, et al. Arthritis Rheumatol 2016:68:1060-71.

Disclosure of Interest: P. Mease Grant/research support from: AbbVie, Amgen, Bristol-Myers Squibb, Celgene, Janssen, Lilly, Novartis, Pfizer, Sun, UCB, Consultant for: AbbVie, Amgen, Bristol-Myers Squibb, Celgene, Crescendo Biosciences, Corrona, Demira, Janssen, Lilly, Novartis, Pfizer, Sun, UCB, Zynerba, Speakers bureau: AbbVie, Amgen, Bristol-Myers Squibb, Celgene, Crescendo Biosciences, Genentech, Janssen, Novartis, Pfizer, UCB, I. McInnes Grant/research support from: Bristol-Myers Squibb, Celgene, Janssen, UCB, Consultant for: BristolMyers Squibb, Celgene, Janssen, Novartis, Pfizer, AbbVie, UCB, V. Strand Consultant for: AbbVie, Amgen Corporation, AstraZeneca, Biogen Idec, BristolMyers Squibb, Boehringer Ingelheim, Celgene, Celltrion, Corrona, Crescendo Biosciences/Myriad Genetics, EMD Serono, Genentech/Roche, GlaxoSmithKline, Janssen, Lilly, Merck, Novartis, Pfizer, Regeneron, Samsung, Sandoz, Sanofi, UCB, O. FitzGerald Grant/research support from: AbbVie, Pfizer, Bristol-Myers Squibb, Consultant for: AbbVie, Pfizer, Bristol-Myers Squibb, Celgene, Janssen, Novartis, UCB, Lilly, H. Ahmad Shareholder of: Bristol-Myers Squibb, Employee of: Bristol-Myers Squibb, A. Johnsen Employee of: Bristol-Myers Squibb, Celgene, Janssen, Novartis, Pfizer, AbbVie, UCB, J. Ye Shareholder of: Bristol-Myers Squibb, Employee of: Bristol-Myers Squibb, S. Banerjee Shareholder of: BristolMyers Squibb, Employee of: Bristol-Myers Squibb

DOI: 10.1136/annrheumdis-2017-eular.1641

\section{SAT0469 INTEGRATED EFFICACY ANALYSIS OF TOFACITINIB, AN ORAL JANUS KINASE INHIBITOR, IN PATIENTS WITH ACTIVE PSORIATIC ARTHRITIS}

P. Nash ${ }^{1}$, L.C. Coates ${ }^{2}$, R. Fleischmann ${ }^{3}$, K.A. Papp ${ }^{4}$, J.J. Gomez-Reino ${ }^{5}$, K.S. Kanik ${ }^{6}$, C. Wang ${ }^{6}$, J. Wu ${ }^{6}$, T. Hendrikx ${ }^{7}$, W.C. Ports ${ }^{6} .{ }^{1}$ Department of Medicine, University of Queensland, St Lucia, Brisbane, Australia; ${ }^{2}$ Leeds Institute of Rheumatic and Musculoskeletal Medicine, University of Leeds, Leeds, United Kingdom; ${ }^{3}$ Metroplex Clinical Research Center and University of Texas Southwestern Medical Center, Dallas, TX, United States; ${ }^{4}$ Probity Medical Research and K Papp Clinical Research Inc, Waterloo, ON, Canada; ${ }^{5}$ Fundacion Ramon Dominguez, Hospital Clinico Universitario, Santiago de Compostela, Spain; ${ }^{6}$ Pfizer Inc, Groton, CT; ${ }^{7}$ Pfizer Inc, Collegeville, PA, United States

Background: Tofacitinib is an oral Janus kinase inhibitor under investigation for treatment of psoriatic arthritis (PsA). 